\title{
Diversity of methodologies to experiment Integrated Pest Management in arable cropping systems: Analysis and reflections based on a European network
}

\author{
Martin Lechenet ${ }^{\mathrm{a}, *}$, Violaine Deytieux ${ }^{\mathrm{b}}$, Daniele Antichi ${ }^{\mathrm{c}}$, Jean-Noël Aubertot ${ }^{\mathrm{d}}$, \\ Paolo Bàrberi ${ }^{\mathrm{e}}$, Michel Bertrand ${ }^{\mathrm{f}}$, Vincent Cellier ${ }^{\mathrm{b}}$, Raphaël Charles ${ }^{\mathrm{g}}$, \\ Caroline Colnenne-David ${ }^{\mathrm{f}}$, Silke Dachbrodt-Saaydeh ${ }^{\mathrm{h}}$, Philippe Debaeke ${ }^{\mathrm{d}}$, Thierry Doré ${ }^{\mathrm{f}}$, \\ Pascal Farcy $^{\mathrm{b}}$, César Fernandez-Quintanilla ${ }^{\mathrm{i}}$, Gilles Grandeau ${ }^{\mathrm{f}}$, Cathy Hawes ${ }^{\mathrm{j}}$, \\ Lionel Jouy $^{\mathrm{k}}$, Eric Justes ${ }^{\mathrm{d}}$, Roman Kierzek ${ }^{1}$, Per Kudsk ${ }^{\mathrm{m}}$, Jay Ram Lamichhane ${ }^{\mathrm{n}}$, \\ Françoise Lescourret ${ }^{\circ}$, Marco Mazzoncini ${ }^{\mathrm{c}}$, Bo Melander ${ }^{\mathrm{m}}$, Antoine Messéan ${ }^{\mathrm{n}}$, \\ Anna-Camilla Moonen ${ }^{\mathrm{e}}$, Adrian C. Newton ${ }^{\mathrm{j}}$, Jean-Marie Nolot ${ }^{\mathrm{d}}$, Silvia Panozzo ${ }^{\mathrm{p}}$, \\ Patrick Retaureau $^{\mathrm{k}}$, Maurizio Sattin ${ }^{\mathrm{p}}$, Juergen Schwarz ${ }^{\mathrm{h}}$, Clotilde Toqué ${ }^{\mathrm{k}}$, \\ Vasileios P. Vasileiadis $^{\mathrm{p}}$, Nicolas Munier-Jolain ${ }^{\mathrm{a}}$ \\ a Agroécologie, AgroSup Dijon, INRA, Univ. Bourgogne Franche-Comté, F-21000, Dijon, France \\ b INRA, UE 115 Domaine Expérimental d'Epoisses, F-21110, Bretenière, France \\ c Centro di Ricerche Agro-Ambientali Enrico Avanzi (CIRAA), University of Pisa, Via Vecchia di Marina 6, 56122 San Piero a Grado, Pisa, Italy \\ ' INRA, UMR1248 AGIR, BP 52627, F-31326, Castanet Tolosan Cedex, France \\ e Institute of Life Sciences, Scuola Superiore Sant'Anna (SSSA), Piazza Martiri della Libertà 33, 56127, Pisa, Italy \\ f UMR Agronomie, INRA, AgroParisTech, Université Paris-Saclay, 78850, Thiverval Grignon, France \\ ${ }^{g}$ Agroscope, Institute for Plant Production Sciences, BP1012, 1260, Nyon, Switzerland \\ h JKI - Federal Research Centre for Cultivated Plants Institute for Strategies and Technology Assessment, Stahnsdorfer Damm 81, 14532, Kleinmachnow, \\ Germany \\ i CSIC, Instituto de Ciencias Agrarias, Serrano 115B, 28006, Madrid, Spain \\ j The James Hutton Institute, Invergowrie, Dundee, DD2 5DA, UK \\ ${ }^{\mathrm{k}}$ ARVALIS Institut du végétal, Service Agronomie, Economie, Environnement, F-91720, Boigneville, France \\ ${ }^{1}$ Weed Science and Plant Protection Department, Institute of Plant Protection - National Research Institute Władysława Węgorka 20, 60-318, Poznań, \\ Poland \\ m Aarhus University, Dept. of Agroecology, Flakkebjerg, DK-4200, Slagelse, Denmark \\ n Eco-Innov Research Unit, INRA, Thiverval-Grignon, France \\ - INRA, UR1115, Plantes et Systèmes de Culture Horticoles, Domaine Saint Paul, site Agroparc, F-84914, Avignon, France \\ p National Research Council (CNR), Institute of Agro-Environmental and Forest Biology, Viale dell'Università 16, 35020,Legnaro (PD), Italy
}

\section{A R T I C L E I N F O}

\section{Article history:}

Received 8 November 2015

Received in revised form

13 September 2016

Accepted 15 September 2016

Available online 31 October 2016

\section{Keywords:}

Cropping system

Field experiment

Integrated pest management

Agroecology

SWOT analysis

\begin{abstract}
A B S T R A C T
Integrated Pest Management (IPM) aims to promote physical and biological regulation strategies that help farmers contain populations of pests (pathogens, animal pests and weeds) and to finally reduce the reliance on pesticides. It is based on the holistic combination of multiple management measures rather than on the sum of single methods, each of them having only small effects on pests reduction. Thus, to analyse the interactions between IPM measures and to evaluate the sustainability of their implementation, we require an approach considering the whole cropping system (CS), i.e. a functional entity whose complexity is more than the sum of its parts. A network of European experiments at the CS level was set up recently, and aimed at sharing data and expertise to enhance knowledge of IPM. Comparison of existing methodologies highlighted a diversity of CS designs and experimental layouts. We deduced that the concept of CS itself was viewed differently among scientists, and this affected experimental protocols. Other differences were related to the research context and objectives. Some experiments aimed to explore very innovative strategies and generated knowledge on both their effects on the agroecosystem and their ability to satisfy a set of performance targets, while others aimed to provide quickly
\end{abstract}

\footnotetext{
* Corresponding author.

E-mail address: martin.lechenet@dijon.inra.fr (M. Lechenet).
} 
adoptable solutions for local farmers in line with the current socio-economic constraints. In some research programmes, the experiment was part of the CS design process - and tested CS were regularly revised based on an continuous improvement loop - while in other cases CS were kept stable across years so as to enable the evaluation of their long-term cumulative effects. A critical aspect contributing to the diversity among CS experiments was the distinction between a factorial design of experimental CS and systemic approaches: factorial experiments allowed quantification of the effects of each IPM component regardless of the consistency between components defining the CS. In contrast, systemic approaches focused on the overall evaluation of CS designed with consideration of their consistency, hence maximising their ability to meet the objectives. Because CS experiments represent a huge investment in terms of economics and time, preliminary reflections of the relevance of the experimental strategy is of critical importance.

(C) 2016 Elsevier B.V. All rights reserved.

\section{Contents}

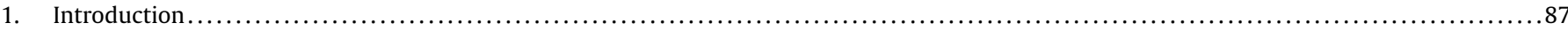

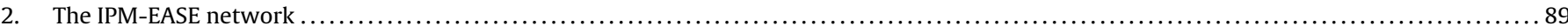

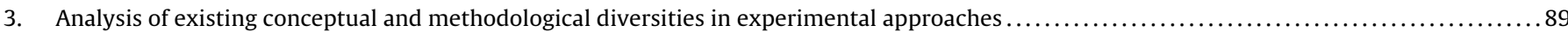

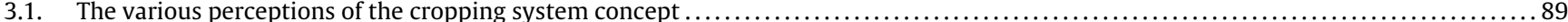

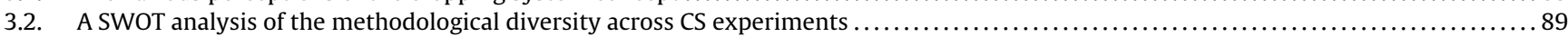

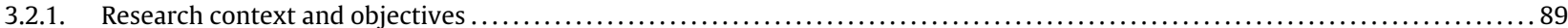

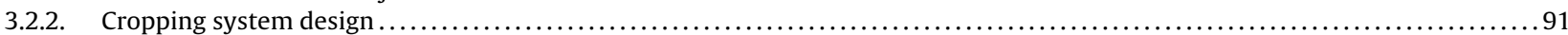

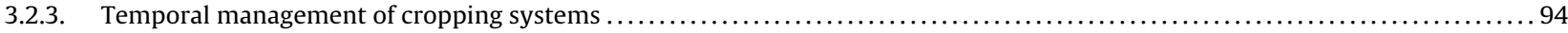



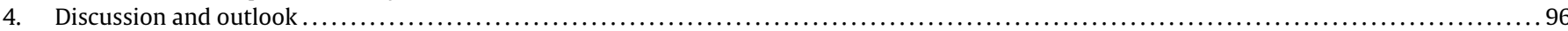

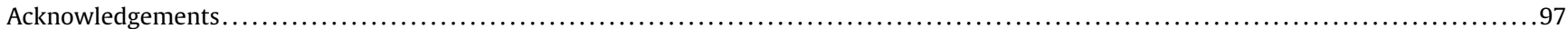

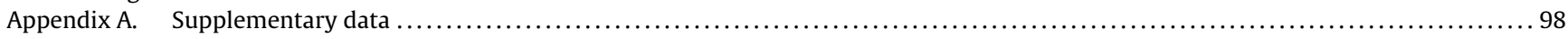

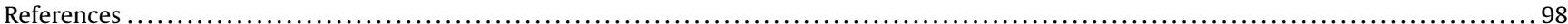

\section{Introduction}

The development of the concept of agroecology (Altieri, 1999; Wezel et al., 2009; Tomich et al., 2011; Duru et al., 2015; Lescourret et al., 2015), which addresses the growing issue of agricultural sustainability, has led scientists to better understand the interactions between cropping practices and environmental components (Matson, 1997; Doré et al., 1997; Steinmann and Gerowitt, 2000). One of the objectives of the agroecological approach is to take better advantage of ecological processes, such as biological regulation of pests (pathogens, animal pests and weeds) (Bianchi et al., 2006), crop pollination (Zulian et al., 2013), or nitrogen supply (Gerowitt and Wildenhayn, 1997; Hauggaard-Nielsen et al., 2009). These processes take place at multiple scales, from the plant to the landscape (Doré et al., 2011; Benoît et al., 2012) and they can be strongly affected by technical management strategies. The management of these processes aims to provide ecosystem services such as food/feed production, climate regulation, reduction of pests or control of soil erosion (Millenium Ecosystem Assessment, 2005; Zhang et al., 2007). The increasing need to reconcile agricultural practices with the various components of sustainability (Foley et al., 2011) was the basis of recent political measures in Europe. Among these measures, Integrated Pest Management (IPM) systems (Directive 2009/128/EC, 2009), aim to foster agroecological approaches (Barzman et al., 2015). IPM is an old concept for pest management which - by prioritizing the combination of a wide range of alternative technical levers to chemicals for pest management - tends to achieve sustainable economic benefits with the lowest risk to human health and the environment (Glass, 1975; Lechenet et al., 2014; Lamichhane et al., 2016). It has previously been at the heart of projects conducted on arable farming systems in the past century (Holland et al., 1994). In the UK, the Boxworth (1981-1988) and the SCARAB (1989-1996) projects aimed to investigate the effects of contrasting pesticide regimes on wildlife (Greig-Smith, 1991; Frampton and Cilgi, 1992), while the TALISMAN project (1989-1996) was primarily set up to investigate the effects of pesticide regimes on crop production and economic profitability (Perks and Lane, 1990). In Germany, the Lautenbach Project (1978-1989) aimed to evolve on-farm Integrated Farming Systems in an interdisciplinary approach (El Titi, 1991) and to test the potential effects of following the rules of IPM. In addition, the INTEX-Project (1989-1997) analysed the effects of cropping systems and management practices focussing on aspects of sustainability, such as production, impacts on the habitat, abiotic regulation (nutrient and pollutant emissions) and social elements (Steinmann and Gerowitt, 2000).

The design of sustainable IPM-based strategies and the assessment of their relevance remains a major priority for the $21 \mathrm{st}$ century agriculture. This requires a holistic approach at the cropping system level, for the following reasons:

(i) A cropping system (CS) is a functional entity whose complexity is more than the sum of its parts (Drinkwater, 2002). Consideration of the CS therefore offers a way to capture the interactions between all farming practices and provides a true representation of the consistency of the technical combination driven by the management strategy (Meynard et al., 2003), i.e. how much the combination of techniques enable the synergies between all components of the CS to serve a goal of sustainability.

(ii) The assessment of agricultural performance at the CS scale allows consideration of the inter-annual effects at the crop sequence level (Sebillotte, 1990), such as the impacts of succeeding crops (e.g. nitrogen supply, disease pressure). This scale is also adapted to study long-term effects of management strategies on parameters of the agroecosystem, including the soil organic matter content (Riley et al., 2008) and the weed seed bank (Moonen and Bàrberi, 2004).

Methods that can be used to study CS include farm surveys, modelling and CS-field experiments. Farm surveys generally aim to (i) provide a better understanding of the links between the diversity of CS and their environment (e.g. regional diagnosis of 
Table 1

Cropping system experiments contributing to IPM-EASE network and their main objectives.

\begin{tabular}{|c|c|c|c|}
\hline $\begin{array}{c}\text { CS field } \\
\text { experiment }\end{array}$ & Location & Key objectives of the experiment & $\begin{array}{c}\text { Starting } \\
\text { year }\end{array}$ \\
\hline $\begin{array}{c}\text { Flakkebjerg CENTS } \\
\text { LTE }\end{array}$ & $\begin{array}{l}\text { Flakkebjerg } \\
\text { (Denmark) }\end{array}$ & \begin{tabular}{|c|} 
Continuous recordings of crop performances and weeds and disease \\
incidences in four crop sequences combined with four tillage regimes \\
ranging from inversion tillage to direct drilling. Annual grass weeds and \\
cleavers (Gallium aparine), crop yields, leaf diseases, N leaching, soil \\
organic matter content and soil physical characteristics have particular \\
interest \\
\end{tabular} & 2003 \\
\hline $\begin{array}{l}\text { Flakkebjerg PURE } \\
\text { field experiment }\end{array}$ & $\begin{array}{l}\text { Flakkebjerg } \\
\text { (Denmark) }\end{array}$ & $\begin{array}{l}\text { Assessing and comparing the performances of three cereal-based CS: a } \\
\text { conventional and two IPM-based systems (with two intensities of IPM) }\end{array}$ & 2011 \\
\hline ICC & Grignon (France) & $\begin{array}{c}\text { Assessing the medium-long term performances of four innovative } \\
\text { cropping systems designed to (i) comply with a main predefined } \\
\text { constraint (low greenhouse gases emissions, or low energy consumption, } \\
\text { or no pesticide use), (ii) satisfy a set of environmental objectives, and (iii) } \\
\text { maintain high production level }\end{array}$ & 2008 \\
\hline IWM-Epoisses & Dijon (France) & $\begin{array}{l}\text { Assessing the medium-long term performances of a range of innovative } \\
\text { CS based on Integrated Weed Management (IWM) }\end{array}$ & 2000 \\
\hline La Cage & $\begin{array}{l}\text { Versailles } \\
\text { (France) }\end{array}$ & $\begin{array}{l}\text { (i) Assessing the performances of a range of wheat-based innovative CS } \\
\text { likely to conciliate a suitable profitability with environmental } \\
\text { preservation. (ii) Providing a package of technical levers adoptable in the } \\
\text { context of the Parisian production basin }\end{array}$ & 1997 \\
\hline LGBI & $\begin{array}{l}\text { Auzeville } \\
\text { (France) }\end{array}$ & $\begin{array}{l}\text { (i) Assessing the effects of grain legumes and cover crops on nitrogen } \\
\text { and water dynamics and CS agronomical and environmental } \\
\text { performances. (ii) Providing regional references and data for crop } \\
\text { models (e.g. Stics) }\end{array}$ & 2004 \\
\hline $\begin{array}{l}\text { Micro-farms of } \\
\text { Boigneville }\end{array}$ & $\begin{array}{l}\text { Boigneville } \\
\text { (France) }\end{array}$ & $\begin{array}{l}\text { Assessing the performances and the feasibility drivers of five farming } \\
\text { systems (integration of work organization constraints for all cropping } \\
\text { operations as in a real farm), and notably their ability to conciliate } \\
\text { productivity and profitability with their proper set of objectives (e.g. low } \\
\text { environmental impact, low workload, low reliance on exogenous N } \\
\text { fertilizers) }\end{array}$ & 1990 \\
\hline RésOPest & $\begin{array}{c}\text { Experimental } \\
\text { network (France, } \\
8 \text { sites) }\end{array}$ & $\begin{array}{l}\text { Produce new references and knowledge useful for the design of } \\
\text { innovative CS less reliant on pesticides by: (i) Designing and assessing } \\
\text { arable and fodder CS using no pesticide, and assessing their agronomic, } \\
\text { environmental and socio-economic performances, (ii) Analysing the } \\
\text { effects of pesticide free CS on pest populations and natural biological } \\
\text { regulations }\end{array}$ & 2012 \\
\hline SGCI & $\begin{array}{l}\text { Auzeville } \\
\text { (France) }\end{array}$ & $\begin{array}{l}\text { Testing experimentally and in practice the CS concept. Assessing the } \\
\text { sustainability of three production strategies corresponding to three } \\
\text { levels of farming intensification. This intensification level is defined by (i) } \\
\text { crop choice, (ii) nitrogen supply and (iii) irrigation }\end{array}$ & 1995 \\
\hline Dahnsdorf LTE & $\begin{array}{l}\text { Dahnsdorf } \\
\text { (Germany) }\end{array}$ & $\begin{array}{l}\text { Comparing the long-term effects of pest management strategies with a } \\
\text { factorial approach on a range of CS in order to: (i) determine the } \\
\text { required necessary pesticide dosage, (ii) assess the sustainability of } \\
\text { different plant protection strategies, (iii) provide a technical package for } \\
\text { plant protection in organic farming }\end{array}$ & 1995 \\
\hline $\begin{array}{l}\text { Dahnsdorf PURE } \\
\text { field experiment }\end{array}$ & $\begin{array}{l}\text { Dahnsdorf } \\
\text { (Germany) }\end{array}$ & $\begin{array}{l}\text { Assessing sustainability and comparing the performances of three cereal- } \\
\text { based CS including a conventional and two IPM-based CS (two levels of } \\
\text { IPM intensity) }\end{array}$ & 2011 \\
\hline CIMAS LTE & Pisa (Italy) & $\begin{array}{l}\text { (i) Assessing the long term agronomic, economic and environmental } \\
\text { effects of integrated (low input) vs conventional management CS. (ii) } \\
\text { Testing a realistic rain fed crop sequence (for an agro-industrial context) } \\
\text { likely to be adopted by local farmers on a short-medium term }\end{array}$ & 1992 \\
\hline $\begin{array}{c}\text { Cona PURE field } \\
\text { experiment }\end{array}$ & Cona (Italy) & $\begin{array}{l}\text { Assessing the effects of introducing a crop sequence starting from a } \\
\text { continuous maize CS infested with a population of Echinochloa crus-galli } \\
\text { resistant to ALS-inhibiting herbicides, and notably evaluating the } \\
\text { possibility of reversing the resistance selection process }\end{array}$ & 2011 \\
\hline Cover crops LTE & Pisa (Italy) & $\begin{array}{l}\text { Comparing the multi-criteria performances of combinations of tillage } \\
\text { systems } \times \mathrm{N} \text { fertilization rates } \times \text { winter cover crop types in order to } \\
\text { provide local farmers with an adapted technical package likely to } \\
\text { improve soil fertility }\end{array}$ & 1993 \\
\hline $\begin{array}{l}\text { Legnaro PURE } \\
\text { field experiment }\end{array}$ & Legnaro (Italy) & $\begin{array}{l}\text { Assessing and comparing the performances of three maize-based CS } \\
\text { including a conventional system and two IPM-based CS (two levels of } \\
\text { IPM intensity) }\end{array}$ & 2011 \\
\hline MASCOT LTE & Pisa (Italy) & $\begin{array}{c}\text { (i) Performing agronomic, economic and environmental assessments of a } \\
\text { five year stockless and rainfed crop sequence managed according to } \\
\text { either conventional or organic strategy. (ii) Providing a technical package } \\
\text { adoptable by local farmers in the short-medium term }\end{array}$ & 2001 \\
\hline $\begin{array}{c}\text { Poznań PURE field } \\
\text { experiment }\end{array}$ & Poznań (Poland) & $\begin{array}{l}\text { Assessing and comparing the performances of three cereal-based } \\
\text { cropping systems: a conventional CS and two IPM-based systems (with } \\
\text { two intensities of IPM) }\end{array}$ & 2011 \\
\hline $\begin{array}{l}\text { Centre for } \\
\text { Sustainable } \\
\text { Cropping (CSC) }\end{array}$ & $\begin{array}{l}\text { Dundee } \\
\text { (Scotland) }\end{array}$ & $\begin{array}{c}\text { (i) A whole-systems, long-term comparison of a conventional vs } \\
\text { sustainable cropping system based on a six year rotation of potato, } \\
\text { wheat, barley, oilseed rape and field beans. (ii) Assessing the effect of } \\
\text { each cropping system on the yield and yield quality for } 5 \text { different } \\
\text { cultivars of each crop }\end{array}$ & 2009 \\
\hline $\begin{array}{l}\text { JHI Dundee PURE } \\
\text { field experiment }\end{array}$ & $\begin{array}{l}\text { Dundee } \\
\text { (Scotland) }\end{array}$ & $\begin{array}{l}\text { Assessing and comparing the performances of three cereal-based } \\
\text { cropping systems: a conventional CS and two IPM-based systems (with } \\
\text { two intensities of IPM) }\end{array}$ & 2011 \\
\hline $\begin{array}{l}\text { Changins crop } \\
\text { rotation LTE }\end{array}$ & $\begin{array}{c}\text { Nyon } \\
\text { (Switzerland) }\end{array}$ & $\begin{array}{l}\text { (i) Testing long term effects of cereal-based crop sequence and soil } \\
\text { tillage on pest dynamic, soil characteristics and CS performance. (ii) } \\
\text { Creating differentiated environments to test other management sub- } \\
\text { strategies (e.g. cultivar choice and fungicide applications) }\end{array}$ & 1967 \\
\hline $\begin{array}{l}\text { Changins soil } \\
\text { tillage LTE }\end{array}$ & $\begin{array}{c}\text { Nyon } \\
\text { (Switzerland) }\end{array}$ & $\begin{array}{l}\text { (i) Testing long term effects of soil tillage on pest dynamic, on soil } \\
\text { characteristics and CS performance. (ii) Creating differentiated } \\
\text { environments to test other management sub-strategies (e.g. choice of } \\
\text { cover crops) }\end{array}$ & 1969 \\
\hline
\end{tabular}

CS experiments in green belong to the PURE European project, the RésOPest network appears in orange. LTE = Long Term Experiment. CS experiments are sorted according to location country and city. commercial fields based on multi-annual on-farm surveys, Norman et al., 1994; Doré et al., 1997), (ii) identify the drivers of CS performance in real farming conditions. This approach is, however, less appropriate when the objective is to assess innovative management strategies based on agronomic breakthroughs that possibly overcome the current regional constraints (e.g. introduction of crops that have so far no market opportunities). In this case, the implementation of appropriate CS-field experiments might be the best way to assess the performance of innovative CS. Anyway, model-based approaches might be preferred to CS-field experiments since the latter are costly, labour intensive, time consuming and can be jeopardized by the lack of long-term funding (Soane and Ball, 1998). Model-based approaches are thus used to test a wide range of agronomic alternatives under a diversity of environmental conditions (Tricault et al., 2009). However, models often fail to properly simulate innovative CS unless they are supplied with data from corresponding field experiments (Rossing et al., 1997; Jégo et al., 2008). CS-field experiments provide an appropriate support to (i) assess CS impact on the different compartments of the environment (Holland et al., 1994; Johnston, 1997), (ii) compare, in a real field context, various production paradigms (Korsaeth and Eltun, 2000; Reganold et al., 2001; Deike et al., 2008) and (iii) discuss management strategies, e.g. crop diversification (Davis et al., 2012), including 'innovative' strategies that are not frequently found in commercial farms. Testing a CS in a realistic field context may also provide an effective communication platform to facilitate the spread of technical knowledge to commercial farms and to highlight further resources needed for the implementation of innovative cropping systems (Wijnands and Vereijken, 1992; Coquil et al., 2014).

Although there is a wealth of evidence from long-term cropping system experiments related to agronomy and environmental concerns (El Titi and Ipach, 1989; Vereijken, 1989; Viaux et al., 1989; Peigné et al., 2009; Sainju et al., 2008; Pardo et al., 2010; see also the review by Johnston, 1997), key questions about the way to set up and conduct CS experiments are scattered in a number of publications that are not always readily accessible and sometimes published in local languages. Schillinger (2010) listed a number of practical points for the success of CS experiments while Debaeke et al. (2009) showed that experiments testing IPM strategies based on explicit decision rules may be conducted according to contrasted methodologies for CS design. By performing a comprehensive review of experimental projects on integrated farming in the 1980 's and 1990 's in Europe, Holland et al. (1994) pointed out a number of specificities in various experimental designs in line with the different objectives as well as financial and logistic constraints. Here we highlight the diversity of existing methods in IPM-based arable CS experiments across Europe, and propose an explicit framework to analyse this diversity by considering a set of key questions to be taken into account before any new field experiment on CS is initiated. We also expect that the proposed classification will be helpful for future IPM experimental programmes and help clarify questions that are disputed among agronomists.

This article is based on a recently established European network of arable CS field experiments named IPM-EASE Network (IPM-based European Arable System Experiments Network). This network was built to: (i) exchange ideas on the way to conduct an IPM-based CS experiment, from design to data analysis, and (ii) assess and compare the performance of IPM-based CS. This network mainly derives from the ENDURE (European Network for the Durable Exploitation of Crop Protection Strategies; http://www.endure-network.eu/), which is a self-sustained European consortium of research institutes, universities and extension organisations supporting IPM. Its main target is to connect the mul- 
tidisciplinary research groups working on IPM in Europe and to create a dynamic scientific community on crop protection.

The first level of diversity identified in the network thanks to the exchanges regards the definition of "cropping system" itself. We described the various perceptions of the concept existing within the network, and we discussed the consequences of these discrepancies on the decisional flexibility for the management of a given cropping system. The second level of diversity concerns practical aspects of experimental schemes. We analysed them through a SWOT analysis (Strengths, Weaknesses, Opportunities, and Threats; Weihrich, 1982). SWOT matrices were built to compare various practical aspects of CS experiments: (i) the general experimental approaches (applied, prospective and patrimonial research experiments), (ii) how the tested cropping systems were designed (factorial vs. systemic design), (iii) how flexible was the CS management over time (fixed vs. iterative design), and (iv) the way the experimental layout could be established (spatial and temporal replication). Finally, we discussed the links between the different levels of diversity we highlighted, and the trade-offs we found between the experimental objectives and the experimental layout.

\section{The IPM-EASE network}

IPM-EASE was established in spring 2013 and remains fully open to new contributors. In 2016, the network gathers 27 CS experiments, mostly on-station, located on 18 sites (Tables 1 and 2). The network is composed of existing experiments set up by various research organisations, which explains the diversity of experimental objectives and CS design. These field experiments are implemented in contrasting bio-physical and socio-economic contexts, they cover a diversity of research questions and therefore they study a wide range of alternative CS, mainly based on IPM (Table 1). Various technical options are tested across this network referring to the crop sequence, cultivars, soil tillage (e.g. inversion tillage, reduced tillage, direct drilling), pest management interventions (mechanical weeding, optimised pesticide doses, site-specific pesticide application) or the management of nitrogen supply. These technical options are not necessarily tested independently but could be combined to best satisfy given objectives (ColnenneDavid and Doré, 2015). Some additional details and feedback of experimenters about their own cropping system experiments are available in Supplementary information 1 and 2.

CS experiments in green belong to the PURE European project, the Rés0Pest network appears in orange. LTE = Long Term Experiment. CS experiments are sorted according to location country and city.

\section{Analysis of existing conceptual and methodological diversities in experimental approaches}

\subsection{The various perceptions of the cropping system concept}

Since the late 1970s, the cropping system has gradually evolved as a major concept in agricultural research. This concept is complex and its evolution over time has led to different definitions (Papy, 2008). Based on the specificities of the IPM-EASE experimental designs, we identified that the perception of the concept among the experimenters varied according to the degree of decisional flexibility that was considered (Fig. 1; Table 2).

The most common perception of a CS (Perception PI in Fig. 1) is based on a strict and narrow understanding of the definition established by Sebillotte $(1974,1990)$. According to this definition, a CS is a sequence of technical operations implemented homogeneously on a set of plots. Each CS is therefore described as a pre-defined crop sequence and a precise set of cropping operations associated with each crop (Sebillotte, 1978). Any changes, either in the cultivar or in the sequence of operations, would therefore result in a different CS. In Fig. 1, wheat (Triticum aestivum L.) is grown on plots 1 and 2 for this given year, while winter rye is grown in plot 3 . This difference in the crop sequence prevents plot 3 from supporting the same CS as plots 1 and 2. Regarding the cropping operation sequence, an herbicide application was performed on plot 1 (high weed infestation in wheat), while no herbicide was applied on plot 2 . According to the previous definition, the three plots consequently would support three different CS.

Another perception of the concept (Perception PII in Fig. 1) defines a CS as a set of decision-making rules governing the cropping operations implemented in a given crop sequence. A decision-making rule is a function which links the decisions to the context elements at the plot scale, including soil and climatic conditions as well as pest pressure (Sebillotte and Soler, 1988; Aubry et al., 1998). Field observations are used as decision criteria and are thus integrated to provide the most adapted solution. The set of decision-making rules allows more flexibility in the management than the previous CS definition, tending to mimic the farmer's decision making process while maintaining the same objectives and management philosophy throughout the experiment. In Fig. 1, plots 1 and 2 share the same set of decision rules and are considered to support the same CS, although the implementation of these rules leads to different sequences of cropping operations in line with different weed pressures (high weed infestation for plot 1, low for plot 2 ). However, a change in the crop sequence results in a different CS, and the CS implemented on plot 3 is here considered as different from the two other plots.

Finally, by further increasing the level of decisional flexibility (Perception PIII in Fig. 1), some experimenters include the choice of successive crop species in the set of decision-making rules defining the CS (Papy et al., 2001). With this perception of the concept, the crop sequence of each CS is not fixed a priori at the beginning of the experiment. Actually, the crop cultivated in a given year may vary depending on agronomic (e.g. soil structure, residual mineral nitrogen, weed/pest/disease infestation) and economic (e.g. targeted gross profit) considerations. In Fig. 1, the set of decision making-rules includes the possibility of cultivating winter rye instead of winter wheat - as the former has a higher weed competitive ability than the latter- if weed infestation after the preceding crop is high. Through this third perception of the CS concept, the various technical managements observed on the three plots correspond to a range of possible outputs for the implementation of the same CS (i.e. the same set of decision rules). One practical advantage of adopting this perception of the CS concept in CS experiments is that this makes it possible to remediate any calamity striking the CS and requiring the destruction of a crop (e.g. excessive pest damage, uneven crop emergence, etc.) and its replacement by another one sown later in the season. In such a case, the management of crop damage might be part of the experiment. If the definition of the tested CS includes an explicit fixed crop sequence, then any replacement of one crop by another for any reason would severely impair the experiment.

\subsection{A SWOT analysis of the methodological diversity across CS experiments}

\subsubsection{Research context and objectives}

We identified three types of experimental approaches according to contrasting expected output: i) applied research; ii) prospective research, and iii) patrimonial research (Table 2). In applied research, the questions integrate current and sometimes local farming issues, and the first objective is to provide practical solutions to farmers in the short-term (Fig. 2). Results and technical packages produced consider local farming constraints (e.g. existing market opportu- 
Table 2

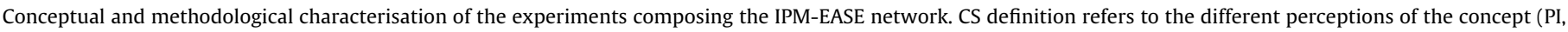
PII, PIII) we discuss in the section 3.1. CS experiments in green belong to the PURE European project while the Rés0Pest network appears in orange.

\begin{tabular}{|c|c|c|c|c|c|c|}
\hline & & & & SWC & Analysis & \\
\hline $\begin{array}{c}\text { CS field } \\
\text { experiment }\end{array}$ & Location & $\begin{array}{c}\text { CS } \\
\text { definition } \\
\text { (PI, PII, } \\
\text { PIII) }\end{array}$ & Main research orientation & CS Design & $\begin{array}{c}\text { Temporal } \\
\text { management }\end{array}$ & $\begin{array}{l}\text { Experimental layout } \\
\text { type of replication }\end{array}$ \\
\hline $\begin{array}{l}\text { Flakkebjerg } \\
\text { CENTS LTE }\end{array}$ & $\begin{array}{l}\text { Flakkebjerg } \\
\text { (Denmark) }\end{array}$ & $\mathrm{PI}$ & Prospective & Tri-factorial & Fixed & Spatial replication \\
\hline $\begin{array}{l}\text { Flakkebjerg } \\
\text { PURE field } \\
\text { experiment }\end{array}$ & $\begin{array}{l}\text { Flakkebjerg } \\
\text { (Denmark) }\end{array}$ & PII & Applied & Systemic & Fixed & $\begin{array}{c}\text { Temporal and spatial } \\
\text { replication }\end{array}$ \\
\hline ICC & $\begin{array}{l}\text { Grignon } \\
\text { (France) }\end{array}$ & PIII & Prospective & Systemic & Fixed & Temporal replication \\
\hline $\begin{array}{l}\text { IWM- } \\
\text { Epoisses }\end{array}$ & $\begin{array}{c}\text { Dijon } \\
\text { (France) }\end{array}$ & PIII & Prospective & Systemic & Fixed & Temporal replication \\
\hline La Cage & $\begin{array}{l}\text { Versailles } \\
\text { (France) }\end{array}$ & PIII & Prospective + patrimonial & Systemic & $\begin{array}{l}\text { Fixed (except for } \\
\text { organic and no-tillage } \\
\text { systems which were } \\
\text { designed with a step- } \\
\text { by-step approach) }\end{array}$ & $\begin{array}{l}\text { Temporal and spatial } \\
\text { replication }\end{array}$ \\
\hline LGBI & $\begin{array}{c}\begin{array}{c}\text { Auzeville } \\
\text { (France) }\end{array} \\
\end{array}$ & PII & Prospective & \begin{tabular}{|c}
$\begin{array}{c}\text { Hybrid systemic- } \\
\text { factorial }\end{array}$ \\
\end{tabular} & Fixed & Temporal replication \\
\hline $\begin{array}{l}\text { Micro-farms } \\
\text { of Boigneville }\end{array}$ & $\begin{array}{c}\begin{array}{c}\text { Boigneville } \\
\text { (France) }\end{array} \\
\end{array}$ & PIII & Applied & Systemic & Fixed & $\begin{array}{c}\text { Temporal and spatial } \\
\text { replication }\end{array}$ \\
\hline Rés0Pest & $\begin{array}{l}\text { Multi-site } \\
\text { (France) }\end{array}$ & PIII & Prospective & Systemic & Iterative & Temporal replication \\
\hline SGCI & $\begin{array}{c}\text { Auzeville } \\
\text { (France) }\end{array}$ & PIII & $\begin{array}{c}\text { Intermediate } \\
\text { applied/prospective }\end{array}$ & Systemic & Iterative & Temporal replication \\
\hline $\begin{array}{c}\text { Dahnsdorf } \\
\text { LTE }\end{array}$ & $\begin{array}{l}\text { Dahnsdorf } \\
\text { (Germany) }\end{array}$ & $\mathrm{PI}$ & $\begin{array}{c}\text { Intermediate } \\
\text { applied/prospective }\end{array}$ & \begin{tabular}{|c}
$\begin{array}{c}\text { Hybrid systemic- } \\
\text { multifactorial }\end{array}$ \\
\end{tabular} & Fixed & $\begin{array}{c}\text { Temporal and spatial } \\
\text { replication }\end{array}$ \\
\hline $\begin{array}{l}\text { Dahnsdorf } \\
\text { PURE field } \\
\text { experiment }\end{array}$ & $\begin{array}{l}\text { Dahnsdorf } \\
\text { (Germany) }\end{array}$ & PII & Applied & Systemic & Fixed & $\begin{array}{c}\text { Temporal and spatial } \\
\text { replication }\end{array}$ \\
\hline CIMAS LTE & Pisa (Italy) & PII & $\begin{array}{c}\text { Intermediate } \\
\text { applied/prospective + } \\
\text { patrimonial }\end{array}$ & Systemic & Fixed & Temporal replication \\
\hline $\begin{array}{c}\text { Cona PURE } \\
\text { field } \\
\text { experiment }\end{array}$ & $\begin{array}{l}\text { Venice } \\
\text { (Italy) }\end{array}$ & PII & Applied & Bi-factorial & Fixed & $\varnothing$ \\
\hline $\begin{array}{c}\text { COVER } \\
\text { CROPS LTE }\end{array}$ & Pisa (Italy) & $\mathrm{Pl}$ & Prospective + patrimonial & Tri-factorial & Fixed & Spatial replication \\
\hline $\begin{array}{c}\text { Legnaro } \\
\text { PURE field } \\
\text { experiment }\end{array}$ & $\begin{array}{c}\text { Padova } \\
\text { (Italy) }\end{array}$ & $\mathrm{Pl}$ & Applied & Systemic & Fixed & Spatial replication \\
\hline $\begin{array}{c}\text { MASCOT } \\
\text { LTE }\end{array}$ & Pisa (Italy) & PII & $\begin{array}{c}\text { Intermediate } \\
\text { applied/prospective + } \\
\text { patrimonial }\end{array}$ & Systemic & Iterative & $\begin{array}{l}\text { Temporal and spatial } \\
\text { replication }\end{array}$ \\
\hline $\begin{array}{c}\text { Poznań } \\
\text { PURE field } \\
\text { experiment }\end{array}$ & $\begin{array}{l}\text { Poznań } \\
\text { (Poland) }\end{array}$ & PII & Applied & Systemic & Fixed & $\begin{array}{l}\text { Temporal and spatial } \\
\text { replication }\end{array}$ \\
\hline $\begin{array}{l}\text { Centre for } \\
\text { Sustainable } \\
\text { Cropping } \\
\text { (CSC) }\end{array}$ & $\begin{array}{l}\text { Dundee } \\
\text { (Scotland) }\end{array}$ & PII & $\begin{array}{c}\text { Intermediate } \\
\text { applied/prospective }\end{array}$ & $\begin{array}{c}\text { Hybrid systemic- } \\
\text { multifactorial }\end{array}$ & Fixed & Temporal replication \\
\hline $\begin{array}{l}\text { JHI Dundee } \\
\text { PURE field } \\
\text { experiment }\end{array}$ & $\begin{array}{c}\text { Dundee } \\
\text { (Scotland) }\end{array}$ & PII & Applied & Systemic & Fixed & $\begin{array}{c}\text { Temporal and spatial } \\
\text { replication }\end{array}$ \\
\hline $\begin{array}{c}\text { Changins } \\
\text { crop rotation } \\
\text { LTE }\end{array}$ & $\begin{array}{c}\text { Nyon } \\
\text { (Switzerland) }\end{array}$ & PII & Prospective + patrimonial & $\begin{array}{c}\text { Bi (or } \\
\text { temporarily } \\
\text { multi)-factorial }\end{array}$ & Fixed & Spatial replication \\
\hline $\begin{array}{l}\text { Changins soil } \\
\text { tillage LTE }\end{array}$ & $\begin{array}{c}\text { Nyon } \\
\text { (Switzerland) }\end{array}$ & PII & $\begin{array}{c}\text { Intermediate } \\
\text { applied/prospective + } \\
\text { patrimonial }\end{array}$ & $\begin{array}{l}\text { Hybrid systemic- } \\
\text { multifactorial }\end{array}$ & Fixed & Spatial replication \\
\hline
\end{tabular}

nities for crops) for a wide adoption by farmers. Feasibility and organisational aspects related to workload distribution over time are often considered as critical aspects to assess (Pardo et al., 2010).

CS experiments with applied objectives provide the opportunity for interactions with farmers (Fig. 2), and may even be implemented in partnership with farmers in their fields (Norman et al., 1994). The experimental layout, which tends to be based on large plots with real farm sized equipment, gives the opportunity to further assess the CS technical feasibility, a key point to ensure the future adoption of the technical packages produced from the results. The interactions with farmers may foster evolutions of the experiment according to technical considerations or observations from farmers. In addition, addressing current issues for commercial farms may also open a greater access to private funding sources.

On the other hand, since CS tested in applied research are, by definition, in line with current systems, drastic changes in crop production are not explored. The level of innovation introduced in the CS design remains limited, and the technical and scientific questions addressed through the experiment may become obsolete in the long-run.

In prospective research, experiments are devoted to the production of scientific and reproducible knowledge coming from a better understanding of (i) agroecological processes which drive
CS performance both in the short and the long-term, and (ii) interactions resulting from combinations of agronomic techniques and their effect on CS performance. The experimental CS are based on a high innovation level in comparison with CS commonly implemented in commercial farms (Fig. 2). Because strategies for pest management are based on prophylactic levers associated with high tolerance thresholds, risks of pest damage are typically unknown at the beginning of the experiment. Crops with no current local market opportunities might be introduced into these systems once they potentially contribute to pest management (Meiss et al., 2010). One of the risks in testing such a strategy is its potentially poor dissemination in the short term among local commercial farms. Nevertheless, this approach provides scientific references for the development of future CS, which may be particularly interesting for different stakeholders (scientists, farmers, policy makers).

The main risk of testing innovative strategies may consist of a failure of CS management due to a lack of technical knowledge, and potential difficulties in reaching the targeted performances (Fig. 2). In addition, a better understanding of agroecological processes generally requires an extensive use of measuring equipment, as well as spending significant time taking measurements. In some cases, the time required to acquire experimental data might conflict with CS management; e.g., time consuming weed counts might conflict 




Three contiguous plots in a given year, which might be considered as supporting either three, two or one unique CS according to the perception of the CS concept. The crop sequence on the three plots is based on winter cereals, either wheat (the most frequent) or rye (when the weed infestation level was high in the previous crop, given its high competitive ability). With the most flexible perception of the $C S$ system concept, the decision rules for weed management could be stated as following:

Rule (i) If the level of weed infestation is high in the preceding crop then winter rye is sown; otherwise winter wheat is sown

Rule (ii) If the level of weed infestation exceeds a threshold provided by a decision support system then it triggers herbicide application

In the presented fictive example, these decision rules triggered the following decision in the considered year:

Plot 1: The weed infestation in the previous crop was medium, so winter wheat was sown. An herbicide treatment was triggered since the weed infestation in wheat exceeded the tolerance threshold.

Plot 2: The weed infestation in the previous crop was medium, so winter wheat was sown. No herbicide application since weed infestation was under the tolerance threshold.

Plot 3: The high weed infestation level of the previous crop triggered the sowing of winter rye instead of wheat. No herbicide application since weed infestation was under the tolerance threshold.

Fig. 1. Impact of the perception of the CS concept on the assignment of three plots to one or several CS.

with mechanical weeding operations that cannot be delayed without a loss in weeding efficiency. The highest priority might then be given to CS management in order to secure CS performance, hence accepting the risk of incomplete experimental datasets ('rather small datasets on a sound CS than large datasets on a CS lacking consistency'). Similar rules are most often adopted when protocols are set up for data acquisition in on-farm experiments.

Some CS experiments, and specifically those devoted to the study of long-term effects of farming practices, have become patrimonial. In such a case the experimental plots might display differentiated biological, chemical or physical states (seed bank, soil organic carbon content, soil structure) resulting from the long-term implementation of contrasting farming practices (Fig. 2). Patrimonial experiments also provide the opportunity to study the robustness of IPM-based CS, i.e. the over-year stability of its performances, with respect to a progressively changing environment. In addition, the differentiated experimental plots are often an attractive support to tackle further research questions. Although these new questions provide evolutionary perspectives for the experiment and make it multidisciplinary, a challenge still lies in updating and enriching the experiment with new research topics and technical innovations without disturbing the management continuity of the patrimonial experiment. To that perspective, new research questions must prioritize novel analytical methods (e.g. nutrient status) or new research fields (e.g. mycorrhiza), rather than new disruptive management techniques.

\subsubsection{Cropping system design}

Although all experiments in the network were based on CS, we identified two contrasting approaches for their design, either based on a factorial combination of techniques or based on a systemic approach (Table 2). The two approaches produce different experimental outputs.

Only a limited number of factors are tested with the factorial approach and the cropping systems studied are the result of all the possible combinations of these factors. The latter can be either quantitative (e.g. $\mathrm{N}$ fertilization rate) or qualitative (e.g. different varieties), or even binary (activated/deactivated, e.g. presence/absence of inversion tillage). The range of CS contributing to the experiment derives from a combination of the management variants for each factor, each factor varying independently from the others and all other attributes being held constant. This enables to (i) separate and quantify the effects of each factor, (ii) study the interactions between these factors, and (iii) determine the opti- 


\begin{tabular}{|c|c|c|c|}
\hline \multirow{2}{*}{$\begin{array}{l}\text { Applied } \\
\text { Research } \\
\text { experiment }\end{array}$} & $\begin{array}{l}\text { Strengths } \\
\text { - Based on current issues } \\
\text { - Feasibility for short term adoption by farmers } \\
\text { - Realistic experimental layout } \\
\text { - Low risk taking }\end{array}$ & $\mathrm{S}$ & $\begin{array}{l}\text { Weaknesses } \\
\text { - lack of innovative prospective }\end{array}$ \\
\hline & $\begin{array}{l}\text { Opportunities } \\
\text { - Exchanges with farmers } \\
\text { - More access also to private funding bodies }\end{array}$ & 0 & $\begin{array}{l}\text { Threats } \\
\text { - Risk of loss of scientific and technical appeal if the } \\
\text { theme becomes obsolete }\end{array}$ \\
\hline \multirow{2}{*}{$\begin{array}{l}\text { Prospective } \\
\text { Research } \\
\text { experiment }\end{array}$} & $\begin{array}{l}\text { Strengths } \\
\text { - High innovation level } \\
\text { - Provide references for future cropping systems }\end{array}$ & $S$ & $\begin{array}{c}\text { Weaknesses } \\
\text { - CS may not be able to reach assigned objectives }\end{array}$ \\
\hline & $\begin{array}{c}\text { Opportunities } \\
\text { - Diversity of targeted stakeholders }\end{array}$ & 0 & $\begin{array}{l}\text { Threats } \\
\text { - Risk of poor dissemination among commercial } \\
\quad \text { farmers } \\
\text { - Possible conflicts between experimental measures } \\
\text { and cropping system management }\end{array}$ \\
\hline \multirow{2}{*}{$\begin{array}{l}\text { Patrimonial } \\
\text { experiment }\end{array}$} & $\begin{array}{l}\text { Strengths } \\
\text { - Long term understanding of agroecological } \\
\text { processes } \\
\text { - Differentiated environments }\end{array}$ & $S$ & $\begin{array}{l}\text { Weaknesses } \\
\text { Difficulties in updating the experimental } \\
\text { management without disturbing the continuation } \\
\text { W of the patrimonial experiment }\end{array}$ \\
\hline & \begin{tabular}{l}
\multicolumn{1}{c}{ Opportunities } \\
- Interesting support for further experiments \\
requiring contrasting environments
\end{tabular} & 0 & $\begin{array}{l}\text { Threats } \\
\text { - Necessity of long term funding }\end{array}$ \\
\hline
\end{tabular}

Fig. 2. SWOT analysis carried out for the various research orientations observed in the IPM-EASE network.

mal trade-offs within the range of tested factors according to the objectives to be achieved (Fig. 3). Classical statistical methods such as ANOVAs are used for identifying factors and interactions with significant effects.

As CS are designed according to a limited number of factors with deliberate contrasting values, they might lack consistency at two levels (Fig. 3): first, it might be possible that none of the tested combinations are fully consistent with the components of the production situation, although this is known to be a critical aspect that affects both CS performance (Boiffin et al., 2001) and feasibility for farmers. Second, as each factor is fixed independently of the others, tested CS might have limited intra-system consistency (between tested factors and with elements that are kept constant for all CS). This may entail difficulties for interpreting the results. For instance, testing the effect of sowing date on weed dynamic over several years with a factorial CS design approach would require an assessment of a range of CS with contrasting sowing dates, by keeping constant all other weeding techniques (García et al., 2014). If herbicide treatments are carried out on the same date for all CS to keep everything but sowing date constant, differences in weed regulation among CS might be due either to sowing dates or to different growth stages of weeds at the date of herbicide application. Indeed, the post-emergence treatment with the same herbicide at the same date and the same dose is likely to be more efficient on young seedlings emerged after the late sowing than on older weeds emerged after the early sowing. In this example, testing consistent CS would have required the combination of early sowings with early herbicide applications on one hand and late sowings with later herbicide applications on the other, thereby leaving out the principle of 'everything else being held constant'.

In contrast with a factorial design, the systemic approach allows the integration of an unlimited number of contrasting techniques into the CS in question, provided that they form a consistent combination. As each CS is designed to best achieve a set of objectives, the measurement of CS performances is a way to assess how consistent is this technical combination.

However, only the effect of the overall combination of techniques can be assessed in CS designed according to a systemic approach. It is not possible to assess statistically the effect of a particular technique independently of the effects of the others (Fig. 3). The experiment of Dijon-Epoisses (see Supplementary information 1 and 2.IV) provides a good example of this point. The CS based on integrated weed management (IWM) included a weed emergence escape strategy, with delayed sowing of winter cereals, to avoid the emergence peak of the major winter weeds (Rasmussen, 2004). This farming practice is combined with other weed management measures (e.g. diversified crop sequence, occasional ploughing, false seed bed technique, mechanical weeding, and herbicide application if necessary), and the control of weeds in the long-term is expected from the combination of all those measures. Cultivars adapted to late sowings are sown in case of delayed sowing. As late sowing is likely to reduce the yield potential for cereals (Pardo et al., 2010), the fertilisation rate is adapted consistently to reduce the cost of inputs and compensate for slightly reduced yields. Moreover, this contributes to reduce the crop disease pressure thereby reducing fungicide frequency and associated cost. Both the specific role of delayed sowing in the weed management and the cost-benefit ratio of this escape strategy remain unknown since delayed sowing is embedded in a combination of measures, and its specific effects cannot be separated from those of the whole management strategy.

Considering the limits of both factorial and systemic approaches, some experiments have taken advantage of the complementarity between factorial and systemic design by introducing factorial trials within plots where consistent cropping systems are tested (as in the SGCI and MASCOT experiments, see Supplementary information 1,2.IX and 2.XV). These factorial trials allow examination of individual technical factors including the cultivar, the fertilisation rate, or cover crops mixtures. In this way, these trials feed the CS prototypes with knowledge about more efficient techniques thereby accelerating the optimisation process.

The design of any CS with a systemic approach must ensure its agronomical consistency through a relevant technical combination. This principle is supported by 'systemic agronomists', who have to advocate the concept while collaborating with scientists from other disciplines. Several CS experiments in the IPM-EASE network are clearly sites for hosting multidisciplinary research that can benefit 


\begin{tabular}{|c|c|c|}
\hline \multirow{4}{*}{ Factorial design } & $\begin{array}{l}\text { Strengths } \\
\text { - Quantifying the effect of each tested factor } \\
\text { - Assessing how tested factors affect cropping } \\
\text { system performances to identify trade-offs }\end{array}$ & \begin{tabular}{l}
\multicolumn{1}{c}{ Weaknesses } \\
- Some tested CS might lack internal consistency \\
- Very labour intensive (high number of treatment \\
combinations)
\end{tabular} \\
\hline & & W \\
\hline & Opportunities & Threats \\
\hline & $\begin{array}{l}\text { Easier valorization of the results in scientific } \\
\text { journals (due to quantification of the effects } \\
\text { coming from each tested factor) }\end{array}$ & $\begin{array}{l}\text { - Testing treatments combinations with all other } \\
\text { attributes being held constant may lead to } \\
\text { questionable results } \\
\text { - Difficulty to make the experiment be a } \\
\text { demonstration platform for farmers }\end{array}$ \\
\hline \multirow{4}{*}{ Systemic design } & $\begin{array}{l}\text { Strengths } \\
\text { - Designing a technical combination according to a } \\
\text { set of performance objectives } \\
\text { - Assessing the consistency of a complex } \\
\text { combination of farming techniques }\end{array}$ & $\begin{array}{l}\text { Weaknesses } \\
\text { - Impossible to distinguish the effect of a technique } \\
\text { from the others }\end{array}$ \\
\hline & & W \\
\hline & Opportunities & Threats \\
\hline & $\begin{array}{l}\text { Exploiting the complementarity between factorial } \\
\text { and systemic approaches }\end{array}$ & $\begin{array}{l}\text { - Risk to lose the system relevance when analytic } \\
\text { questions get higher priority than making a CS } \\
\text { consistent with a set of objectives }\end{array}$ \\
\hline
\end{tabular}

Fig. 3. SWOT analysis carried out for the two types of experimental design observed in the IPM-EASE network.

\begin{tabular}{|c|c|c|c|}
\hline \multirow{2}{*}{$\begin{array}{l}\text { Fixed cropping } \\
\text { system }\end{array}$} & \begin{tabular}{l}
\multicolumn{1}{c}{ Strengths } \\
- Robustness of the results \\
- Easy comparison between cropping systems \\
- Studying the trajectory of (i) the environment \\
and (ii) cropping system performances
\end{tabular} & S & $\begin{array}{l}\text { Weaknesses } \\
\text { - No ongoing improvement of cropping system } \\
\text { management } \\
\text { W }\end{array}$ \\
\hline & $\begin{array}{c}\text { Opportunities } \\
\text { - Approach leading to differentiated environments }\end{array}$ & $\mathrm{O}$ & $\begin{array}{l}\text { Threats } \\
\text { - Risk of irreversible deterioration of the } \\
\text { experimental support }\end{array}$ \\
\hline \multirow{3}{*}{ Iterative-design } & \begin{tabular}{l}
\multicolumn{1}{c}{ Strengths } \\
- Providing optimized cropping system \\
- Linking the evolution of the CS to the trajectory o \\
performances
\end{tabular} & & $\begin{array}{l}\text { Weaknesses } \\
\text { - As cropping system evolves over time, creates } \\
\text { additional difficulties to identify the drivers of } \\
\text { cropping system performances } \\
\text { - Difficulties in comparing the performances of the } \\
\text { different treatments over time due to the changes } \\
\text { in the combination of techniques }\end{array}$ \\
\hline & Opportunities & 0 & Threats \\
\hline & $\begin{array}{l}\text { - Dynamism around the way to improve cropping } \\
\text { system prototype } \\
\text { - Production of knowledge about (i) CS design } \\
\text { methods and (ii) technical resources needed for } \\
\text { the implementation of innovative CS }\end{array}$ & & - Possible difficulties in interpreting the results \\
\hline
\end{tabular}

Fig. 4. SWOT analysis carried out for the two approaches of temporal management of the cropping systems observed in the IPM-EASE network.

from innovative cropping practices and/or contribute to the evaluation of the IPM-based CS prototypes. The diversity of research fields tends to enhance the scientific productivity. However scientists from other disciplines such as soil microbiology, plant pathology or plant breeding might not be familiar with the systemic approach. Combination of the expectations of multiple contributors within the same experiment might become a difficult task which requires identification of trade-offs between the scientific approaches of the different contributors. Otherwise, the risk is to reduce the flexibility for the experimental design and operations (e.g. plot size, cultivar choice, organizational aspects for data acquisition), and even to reduce the agronomic relevance of the CS when many variants have to be tested to satisfy the requirements of all the scientific partners (Fig. 3).

The type of CS design process (factorial vs. systemic) might have consequences for the status of control plots and reference CS, a critical point that must be carefully considered when initiating a CS experiment. In factorial CS experiments, one particular combination of factors might be considered as a control. The control plot might be either the combination with no specific measure for pest management or with the lowest level of inputs, or it might be the closest CS to local standard practices. In CS experiments that follow a systemic approach, the status of control plots and reference systems is different. CS experiments aim at testing the capacity of innovative management strategies to attain the objectives for which they were designed (Meynard et al., 2012). Thus, a reference CS is not mandatory, and the evaluation of tested CS (e.g. IPM-based CS) might be performed by comparing the performances obtained with target performances fixed a priori for each CS (Steinmann and Gerowitt, 2000; Colnenne and Doré, 2015). In the assessment of cropping systems sustainability, such target performances can be defined (i) by normative reference values established from published scientific knowledge, expertise, political decisions or regulations, (ii) by reference values established from one or several systems (Deytieux et al., 2016). However most CS experiments with a systemic approach in the IPM-EASE network included a reference system providing reference values for all the components of the evaluation. The values of yield, net profit, treatment frequency, etc. observed in the reference system are typically used to interpret the performances of each alternative 
CS, and occasionally performance might be expressed as relative values compared to reference values. In all cases when the experimental scheme included a reference system, it was designed so as to be in line with the current local standard agricultural practices in the area. In this way, IPM-based CS might be evaluated as potential alternatives for the corresponding agricultural context. Although defining local standard practices might be difficult in areas with a high local diversity of farming systems, the comparison of assessment indicators of IPM-based CS with those of the reference CS proved to be very useful in terms of communication of the results. This is particularly true for indicators that remain unusual for farmers so far, such as indicators of greenhouse gas emission, or indicators of eco-toxicity (Deytieux et al., 2012). Several experimenters experienced difficulties in managing a reference CS independently of other prototypes of the experiment while keeping in mind the specific objectives and sets of decision rules of each CS, and avoiding the influence of information available from other CS for decision making in the reference CS. These difficulties, and therefore the risk of "management mistakes", increase when tested CS are numerous and tested management strategies are contrasting. Some experiments of the IPM-EASE network, such as the ICC experiment (see Supplementary information 1 and 2.III), do not have their own local reference system. Reference values used for the evaluation of CS prototypes, with respect to current local standard agricultural practices, had then to be found elsewhere, i.e. from data outside the experiment. Some CS experiments (e.g. SGCI and LGBI, see Supplementary information 1 and 2.IX, 2.VI) also included 'within CS control plots' that were typically small areas of several $\mathrm{m}^{2}$ with either 'no pest control' or 'full pest control'. These CS control plots were used either for the specific evaluation of one decision or for assessment of one key variable useful both to understand the CS and to interpret the results (e.g. estimation of the potential yield, or evaluation of the change in potential weed emergence over time).

\subsubsection{Temporal management of cropping systems}

In CS experiments designed to address the cumulative effects of a given technical combination, the experimental management has to maintain as far as possible a fixed CS over time (Table 2). By avoiding any changes in the sets of decision rules, it is possible to evaluate the effects of CS on physical, chemical or biological variables that change over time, such as the soil organic matter content or the weed seed bank. The continuation of fixed CS over time also makes it possible to grasp the dynamic of new regulation processes that requires time before the expected ecological functions become evident. For instance, CS designed to favour predators of slugs would permit the build-up of ecological regulation services (Symondson et al., 2002). However, this process might not be efficient in the first seasons and thus might require several years of fixed CS before ecological regulations gradually begin to operate. As the avoidance of chemical pesticides for control of slugs is one of the essential components to foster slug predators (Nash et al., 2008), the crop yield is likely to be severely affected during the first years. The outputs of such a CS experiment with fixed decision rules would provide information about (i) the required duration for the establishment of ecological regulation of slugs, and (ii) the efficiency of the regulation service compared to anti-slug applications. However, practical drawbacks of keeping absolutely fixed CS might arise if the combination of techniques is less effective with the consequent risk of irreversible deteriorations (e.g. weed seedbank build-up) likely to compromise the entire experiment.

Conversely, in the MASCOT experiment and other experiments in France (Rés0pest, SGCI, see Supplementary information 1 and 2 ), the experiment was considered as part of the CS design process adopting an iterative approach based on a "trial and error" cycle, with a step by step adjustment of the technical combina- tions and associated decision rules. This continuous improvement of the technical management ensures a consistent and realistic implementation of farming practices, with the objective of progressively approaching to the best possible CS performance. A gradual improvement strategy requires a continuous assessment of the strengths and weaknesses of the CS, enabling positive interactions between actors involved in the experiment (Fig. 4). In the case of the MASCOT experiment, 'field days' were frequently organised with local farmers. The experiment has become a demonstration platform favouring exchanges, feedback and suggestions for the improvement of experimental CS. Although this approach had a great potential to improve the strategy implemented, allowing the system management to evolve over time is likely to hinder the scientific interpretation of the links between CS performance and their potential drivers, along with difficulties to compare CS (Fig. 4).

The two above-described approaches in CS temporal management (fixed vs. iterative design) are two extreme options. Actually, most of the experiments in the IPM-EASE network allow adjustment of their CS at various time scales (e.g. each year in the case of iterative design, each half crop sequence cycle or each full crop sequence cycle). These adjustments may be anticipated and formalised through meta-decision rules, providing flexibility in the evolution of the technical combinations in line with the local perception of the CS concept. In the MASCOT experiment, complementary adjacent factorial trials were used to test new species and mixtures as potential cover-crops, and an explicit meta-decision rule stated that a cover crop that would appear more competitive than those currently used could be introduced in the CS experiment.

\subsubsection{Experimental layout}

The experimental layout (i.e. how the CS experiment is organised in space and time) is another important aspect of the experimental diversity that we identified in the IPM-EASE network (Table 2).

Almost all the experiments in the IPM-EASE network included replications of tested CS, so that replicated data could be subjected to statistical analyses allowing a validation of the observed effects. The only experiment without any real replicate was the Cona PURE field experiment, which was the only on-farm site, all the other sites being managed by experimental stations. However, the design of replicates varied across sites, in line with differences in the perception of the CS concept. A majority of sites included the so-called 'spatial replicates' (i.e. several plots corresponding to the same CS and the same crop in the crop sequence pattern; Table 2). Spatial replicates shared the same sequence of cropping operations in sites where the perception I of the CS concept was used. At the same time, spatial replicates shared the same set of decision rules in sites where definition II was used. Spatial replicates are particularly useful in case of high soil spatial heterogeneity that is likely to create variability in CS performances (Figs. 5 and 6).

When no spatial replicates of the tested CS are available, experimental protocols may include replicates of measurements within a given plot, as it is the case in the Cona PURE field experiment. However, these "pseudoreplications" have been extensively criticised (Hurlbert, 1984), because in such a case statistical methods are unable to separate the effects of intrinsic inter-plot heterogeneity from the confounded effects of tested CS. When no true replicates can be set up, it is worth to consider a meta-analysis over a range of sites as an alternative.

A majority of IPM-EASE sites included 'temporal replicates' of tested CS. In case of temporal replicates, plots corresponding to a given CS are grown in a given year with different crops of the crop sequence pattern. Replicates are not those of the sequence of technical operations (hence temporal replicates are not consistent with the perception I of the CS concept), but are those of the set of decision rules implemented across a climatic variability gener- 


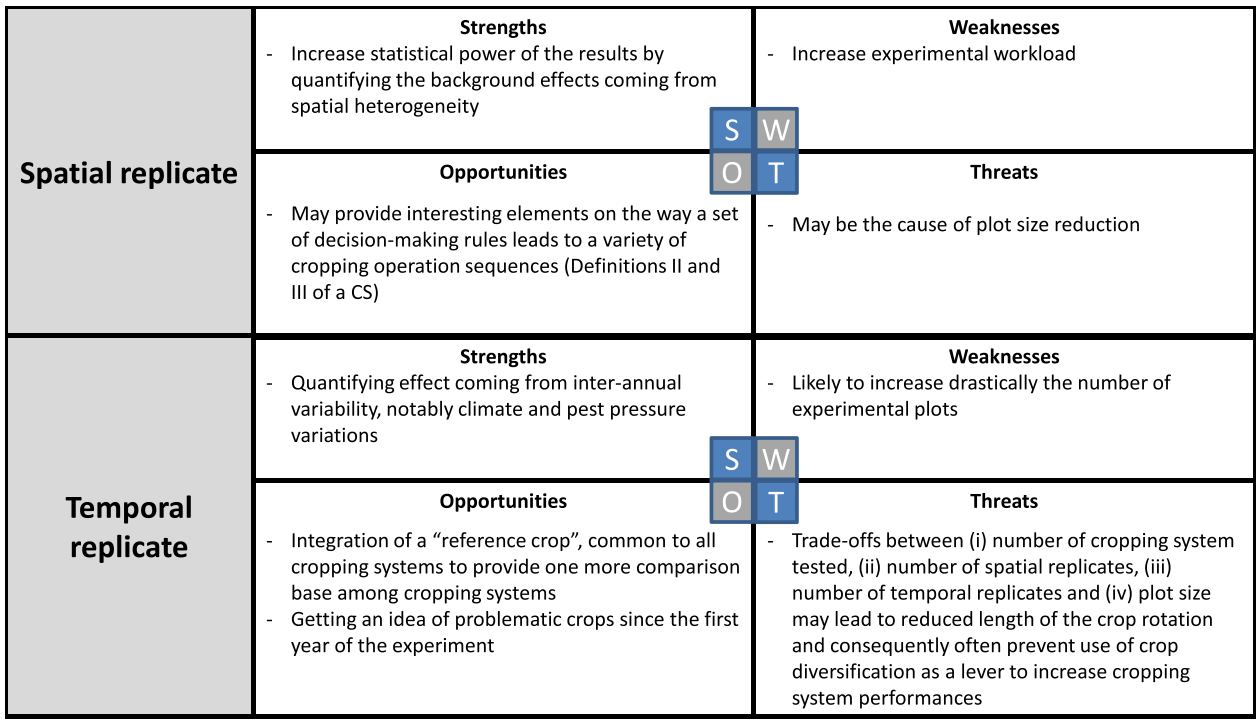

Fig. 5. SWOT analysis carried out for the two types of experimental layouts observed in the IPM-EASE network.

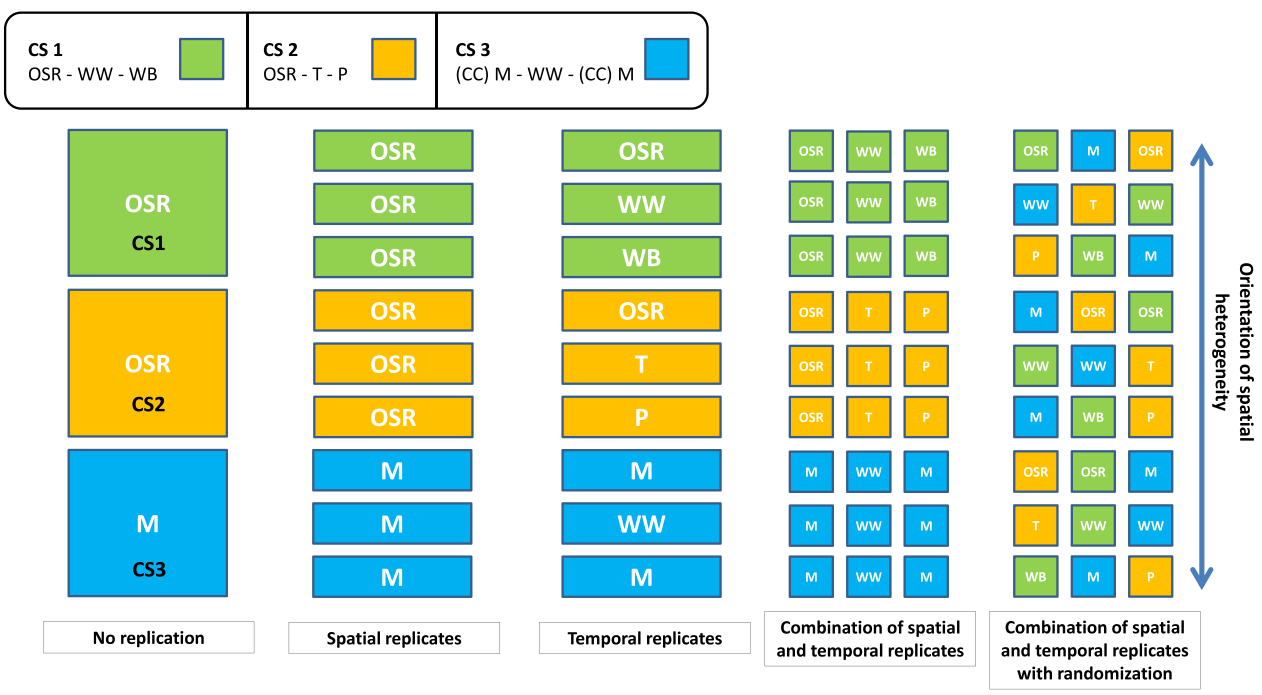

Fig. 6. Example of experimental layouts with different types of replication strategy.

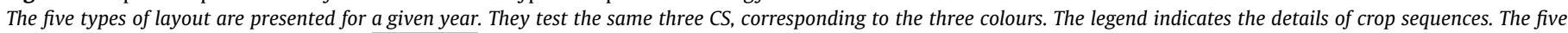

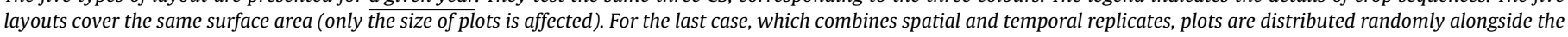

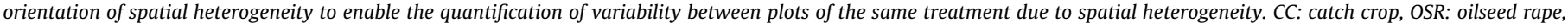
WW: winter wheat, WB: winter barley, T: triticale, P: spring pea, M: maize

ated due to the differences in the weather of the following years (Fig. 5). This type of experimental layout requires that most variables are collected at the CS level. Statistical tests might then be used to analyse for instance the effects of CS on the cumulative Treatment Frequency Index (Kudsk and Jensen, 2014) or on indicators of economic profitability, all computed at the CS level. In such designs, it would not be really sound to compare variables collected at the crop level such as the crop yield in a given year, provided that several crop species are grown each year. However, after several years, it is still possible to use statistical tests to compare the distribution of yields obtained across years for a single crop (e.g. wheat or maize) in different CS. This allows analysis of the effect of CS on yields for this particular crop.

One option for experimental layout with temporal replicates is the case where all the crops of the crop sequence pattern are grown each year for each CS. Then the number of plots required for temporal replication is related to the duration of the crop sequence. This may either increase drastically the number of experimental plots, or reduce the duration of crop rotations, which would consequently exclude an important IPM measure for arable crops (Fig. 5). This type of experimental layout matches only with the definition II of the CS concept, because with such a layout option the crop sequence must be fixed at the beginning of the experiment, which limits the potential for crop sequence flexibility foreseen with the definition III of the CS concept. Growing all the crops of the crop sequence each year ensures a better assessment of the effects coming from inter-annual variability of the weather and of pest pressure on CS performances. This provides a picture of the whole crop sequence since the first year of the experiment, which might accelerate the trial/error cycle associated with iterative-design approaches. The option of growing all crops of the rotation every year may give the opportunity to select a "reference crop" common to all tested CS. Such a "reference crop" strengthens the assessment of the CS effect (e.g. pests pressure, available nitrogen) and may be partic- 
ularly interesting in providing an additional comparison between CS when the length of the crop sequence is different from one CS to another.

Six experiments in the IPM-EASE network (namely MASCOT, La Cage, the PURE experiments in Flakkebjerg, Poznan, JHI Dundee and Dahnsdorf, the Micro-farms of Boigneville experiment and Dahnsdorf LTE, see Supplementary information 1 and 2) combined spatial and temporal replications thereby increasing the number of treatment plots, up to 648 in Dahnsdorf LTE. The increase in the number of replicates conflicts with the size of experimental plots (Fig. 6), and therefore drastically influences the management of the experiment. At the scale of the experimental research unit the available space to set up a CS field experiment is often limited and therefore the experimental design must integrate a trade-off between (i) the number of CS tested, i.e. the number of management variants, (ii) the type and number of replicates, (iii) the duration of the crop sequence (when the option of 'all crops of the rotation grown every year' is chosen), and (iv) the size of plot units. In several experiments which included temporal replication, such as in most of PURE field experiments, the duration of the crop sequence was deliberately limited to keep a reasonable number of plots whilst still maintaining a suitable plot size. In some cases, the duration of a funded research project may also be a limiting factor for the diversity of the crop sequences.

The size of individual plots in IPM-EASE ranged from $25 \mathrm{~m}^{2}$ (CENTS in Flakkebjerg) to 50,000 $\mathrm{m}^{2}$ (Micro-farms of Boigneville). Small plot size associated with an experimental patchwork of crop types might affect the dynamic of pests as compared to real agricultural landscapes (Holland et al., 1994). This effect of spatial fragmentation might skew the observed level of pest control in CS prototypes. Likewise, the ratio length of field edges:plot area is higher in small plots, which increases the risk of edge effects. From a technical point of view, a small plot size is likely to influence the decision-making process in field experiments where CS are defined as a set of decision-making rules: tolerance thresholds that trigger decisions may be reached differently than in a realistic field context (e.g. what is only a foliar disease patch in a large field could become a full infestation in a small one). Finally, the size of experimental plots also determines the type of equipment that can be used for crop management. Some techniques such as mechanical weeding require large (several meters) and long (several tens of meters) plots. The trade-off between plot size and the number of replicates is particularly challenging for on-farm experiments, where field operations are implemented by farmers themselves. Usually, one of the conditions required by farmers when negotiating their active involvement in research is the layout of the experiment. Indeed, the layout should be compatible with farmers' system to avoid waste of time and mistakes while performing treatments. To facilitate farmers' operations, experimenters may decide to set up the experiment without a rigid randomization, although this would decrease scientific rigor.

Experimental plot connectivity and landscape features must be accounted for in IPM experiments. Field margin management is often presented as an effective lever to enhance semi-natural area within farmland and to benefit from ecological services supplied by biodiversity (Marshall and Moonen, 2002). Many polyphagous predators have significantly higher densities close to margins $(15-30 \mathrm{~m})$ and beetle banks enhance predator densities within neighbouring crop rows (Boatman, 1994). Several experiments in the network included landscape features potentially contributing to biological regulations, such as grass strips (IWM LTE DijonEpoisses), hedges and margins sown with perennial wildflower mix (CSC Dundee). However, the management of field margins has rarely contributed to the discrimination of the tested CS as the effects can be expected only at the landscape level. Enhanced biological regulations were mostly expected to benefit pest man- agement over the whole relevant experiments. The CSC experiment in Dundee was the only site where the management of field margins differed among the tested CS, as the perennial flowering vegetation was sown only in the margins of the 'sustainable' treatments. This was possible thanks to the large size of plots (about 3-4 ha), and enabled surveys of natural enemies and pollinators to be carried out. Most often, the management of between-plot alleys was decided to avoid potential disturbance to within-plot pest dynamics although the management options differed across sites. Between-plot alleys were either intensively tilled - in order to keep the experiment within a neutral environment by avoiding both the effects of alleys and adjacent CS (e.g. ICC Grignon) - or sown with grass to shield a given plot from the effect of the adjacent ones, and to avoid between-plot weed dissemination (Cordeau et al., 2011). Endocyclic pests, as defined by Aubertot and Robin (2013), have little risk of interaction between plots. However, tillage operations might disperse endocyclic pests' inocula sensu lato (such as pathogenic agents responsible for soil-borne diseases, weed seeds, or eggs or adults of endocyclic animal pests). It is therefore important to perform a careful sanitation of tillage equipment and pneumatics to prevent cross-contaminations among experimental plots. It is not possible to prevent dispersal of non-, or slightly endocyclic pests. As physical barriers between plots, such as rye strips, are not fully efficient, it might be recommended to avoid observations on the edge of the experimental plots since they are not representative of the agroecosystems in question. The width of this edge effect depends on the type of organism and may be even larger than the experimental plot itself. One way to overcome the problem of cross-contaminations is to analyse the spatial distribution of statistical residuals and to integrate ad hoc corrections in the statistical analysis (Kempton, 1997; Durban et al., 2001). Hedgerows and other physical barriers are expected to reduce pesticide drift (Lazzaro et al., 2008). For instance, in the MASCOT experiment, hedgerows were planted to separate the organic CS from the conventional one. The management of those landscape features (e.g. hedgerow pruning, grass strip mowing, re-sowing) is a key factor to reduce risks of cross-contaminations, but also impacts on microclimate and soil conditions at the crop edge. For instance, the regular cutting of field margins is commonly associated with the reduction of ergot (Claviceps purpurea Tul.) that spreads from the margin to the surrounding cereal crops (Bayles et al., 2009). The retention of a grass cover between plots may also increase the load bearing capacity of the ground and therefore facilitate the access for farming equipment, experimental equipment and staff.

\section{Discussion and outlook}

The different aspects of diversity we identified within the IPMEASE network of CS experiments are actually not independent from each other. Both the perception of the CS concept and the objectives assigned to the experiment clearly shape the experimental design adopted in the different sites (Table 2). We identified five major objectives in IPM experimental research on CS, some experiments potentially pursuing several objectives:

- Objective 1: Quantification of the effects of CS components and their interactions. This type of issue is generally addressed through factorial trials, most often in line with the definition I of the CS concept (i.e. a sequence of cropping operations). This objective necessitates the "everything else being held constant" rule, to measure and separate the effects of CS components. Isolating the effect of tested factors from the effect of spatial heterogeneity requires several spatial replicates, which contributes - along with the high number of CS tested - to the substantial 
reduction of plot size. The technical management remains, as far as possible, fixed over time.

- Objective 2: Design of innovative CS through the experimental iterative approach. Iterative-design of CS is mostly associated with systemic approaches since its purpose is to get the most consistent technical combination with regard to the target objectives assigned. The iterative approach refers to the second and third perceptions of the CS concept, with a critical importance given to the definition and adaptation of consistent decision-making rules. Plots supporting the same CS therefore replicate a set of decision rules leading possibly to different cropping operation sequences. This adaptive management of CS may benefit from new technical options, derived from concurrent factorial trials that address a particular aspect of CS management.

- Objective 3: Assessment of the feasibility of CS prototypes in view of the objectives and constraints assigned to each prototype. In this case, data collection is organised to evaluate the ability of CS to satisfy a set of objectives, generally a range of target performances, under different constraints (e.g. a rain-fed cropping system). The design of the tested CS tends to mimic the decision making in commercial farms, where objectives and constraints are the main drivers of implemented strategies. In the same way as for iterative-design, CS are defined as sets of decision making rules which may lead to different cropping operation sequences across plots. The systemic approach is consistent with this objective, as the aim is to combine techniques into a strategy that fits to the objectives to be fulfilled. Each CS might have its own set of objectives and constraints. CS performances might then be evaluated as compared to their own target, but comparison between CS is also possible, more particularly when the objectives assigned are defined on the basis of the performances of a reference CS (e.g. economic profitability must be the same as that of the conventional system).

- Objective 4: Evaluation of long-term cumulative effects of CS prototypes. This objective might be regarded as a variant of the previous one. The specificity of this objective is that CS are evaluated in the long-term to assess cumulative effects on biophysical compartments (e.g. evolution in soil structure or in weed flora). As the aim here is to measure changes in the agroecosystem, tested CS are fixed over time as far as possible.

- Objective 5: Understanding how CS influence the processes underlying pest dynamics and damages. This objective might be based either on factorial or systemic approaches. Generating knowledge requires many observations and measurements on contrasting CS and control plots to characterise the response of the agroecosystem. In such a case, the on-going agroecological transition should renew methodological approaches: when pesticides were offering a chemical umbrella to limit damages caused by pests, observations and measurements were used to focus on crop development (phenology, biomass, Leaf Area Index, etc.) and abiotic stresses. At present, biodiversity should play a major role in agroecosystems and the number of variables to be examined in a given CS experiment should increase to better grasp its interactions with the other components of the agroecosystem. Besides the development of bio-indicators and automatic data collection, one way to increase the number of observations in cropping system experiments could be a more frequent use of qualitative scales (ordinal variables) to characterise the biocenosis. The characterisation of processes affected by CS is complex and may cover multiple research fields. Measurement of indicators over a wide range of system components would develop the experiment as a multidisciplinary research platform.

In all of the CS experiments - regardless of the research objectives pursued - the behaviour of the agroecosystem depends both on the tested CS and on the production situation. Although the principles of the decision-making are easily extrapolated, the experimental outputs are site-specific thereby raising the question of the generic value of the knowledge produced. One way to increase the validity domain and thus the generic value of the results consists in the consideration of a common research question at the scale of an experimental network. Networking allows a cross-reflection between the experimenters from the first steps of the experimental design (see the example of RésOPest and PURE experiments in Supplementary information 1 and 2). It facilitates the sharing of experience and technical knowledge that are critical for the implementation of innovative cropping systems (Meynard et al., 2012). It enables also a cross validation of the results, which is useful to address the question of their generic value. Provided that protocols are written to standardise data collection among experimental sites, working at the scale of an experimental network might moreover produce datasets for statistical analyses when replicates of CS are lacking in each site.

Sharing experiences and analysing the diversity of methodological approaches was the first joint activity of the IPM-EASE European network. A further networking action will be to create a common database with technical details for each IPM-EASE CS. This database will support analyses - both to assess CS performances and to identify multi-purpose and sustainable CS - hence contributing to the identification of robust IPM strategies for European agriculture. The review and analysis we present here might thus encourage the launching of new CS experiments and help the designers of those new experimental initiatives make better methodological choices in accordance with their research objectives. We recommend that anyone wishing to launch a new CS experiment should thoroughly examine all the issues addressed here, given that the initial methodological choices might have long-lasting consequences. Considering the major challenge for agriculture, i.e. reconciling crop productivity and profitability with limited environmental impacts, we also recommend adopting holistic research approaches wherever possible. We recommend studying farming systems with strong internal consistency as well as in line with the surrounding environment. This is key to the design and study of potentially more sustainable farming systems.

\section{Acknowledgements}

The authors thank ENDURE network of excellence and the GIS HP2E GC for their contribution to the establishment of IPMEASE network. The research leading to these results has received partial funding from the European Union Seventh Framework Programme (FP7/2007-2013) under the grant agreement $n^{\circ} 265865$ (PURE project).

The Rés0pest project is funded within the Ecophyto French national Plan, by the DEPHY-EXPE volet. We thank all experimenters of the Rés0pest network.

We thank the INRA/CIRAD Integrated Pest Management Network.

In the past the COVER CROPS trial has received funding from the MIPAAF-PANDA and from FP7-KBBE 289277 OSCAR (2012-2016), the CIMAS trial from the LIFE11 ENV/IT/000302 IPNOA(2011-2015) and from the MIPAAF-PANDA, and the MASCOT from ERANET Core Organic Plus FERTILCROP (2015-2017), ERA-NET Core Organic II TILMAN-ORG (2011-2014), FP7-KBBE 245058 SOLIBAM (2010-2014), MIUR-FISR SIMBIOVEG (2006-2008) and MIPAAF BIOCER (2004-2006).

The LGBI experiment was supported by the FP6 Grain Legumes Integrated Project (Food-CT-2004-506223) and INRA. We also acknowledge the French Ministry of Agriculture for funding the CASDAR Leg-N-GES project coordinated by Jean-Pierre Cohan (Arvalis Institut du Vegetal). 
Fermes de Boigneville received funding from the CSDAR, the Conseil Général d'Île de France, the PURE project, the ONEMA (Ecophyto), and Arvalis-Institut du vegetal.

The 'JHI Dundee PURE field experiment' and the 'Centre for Sustainable Cropping (CSC) Dundee Scotland' were partially funded by the Scottish Government under its "Sustainable Agriculture-Plants" programme and from 2016 under its Strategic Research Programme-“Sustainable Land Management and Rural Economies.

\section{Appendix A. Supplementary data}

Supplementary data associated with this article can be found, in the online version, at http://dx.doi.org/10.1016/j.eja.2016.09.012.

\section{References}

Altieri, M.A., 1999. The ecological role of biodiversity in agroecosystems. Agric. Ecosyst. Environ. 74, 19-31.

Aubertot, J.-N., Robin, M.-H., 2013. Injury Profile SIMulator, a qualitative aggregative modelling framework to predict crop injury profile as a function of cropping practices, and the abiotic and biotic environment I. Conceptual bases. PLoS One 8, e73202.

Aubry, C., Papy, F., Capillon, A., 1998. Modelling decision-making processes for annual crop management. Agric. Syst. 56, 45-65.

Barzman, M., Bàrberi, P., Birch, A.N.E., Boonekamp, P., Dachbrodt-Saaydeh, S., Graf, B., Hommel, B., Jensen, J.E., Kiss, J., Kudsk, P., Lamichhane, J.R., Messéan, A., Moonen, A.-C., Ratnadass, A., Ricci, P., Sarah, J.-L., Sattin, M., 2015. Eight principles of integrated pest management. Agron. Sustain. Dev. 35, 1199-1215.

Bayles, R., Fletcher, M., Gladders, P., Hall, R., Hollins, W., Kenyon, D., Thomas, J., 2009. Towards a sustainable whole-farm approach to the control of Ergot. In: HGCA Project Report, 173 pp.

Benoît, M., Rizzo, D., Marraccini, E., Moonen, A.C., Galli, M., Lardon, S., Rapey, H., Thenail, C., Bonari, E., 2012. Landscape agronomy: a new field for addressing agricultural landscape dynamics. Landscape Ecol. 27, 1385-1394.

Bianchi, F., Booij, C.J.H., Tscharntke, T., 2006. Sustainable pest regulation in agricultural landscapes: a review on landscape composition, biodiversity and natural pest control. Proc. R. Soc. B Biol. Sci. 273, 1715-1727.

Boatman, N., 1994. Field Margins: Integrating Agriculture and Conservation. British Crop Protection Council, Surrey, England, 404 pp.

Boiffin, I., Malezieux, E., Picard, D., 2001. Cropping systems for the future. In: Nösberger, J., Geiger, H.H., Struik, P.C. (Eds.), Crop Science: Progress and Prospects. Cab International, pp. 261-279.

Colnenne-David, C., Doré, T., 2015. Designing innovative productive cropping systems with quantified and ambitious environmental goals. Renew. Agric. Food Syst. 30, 487-502.

Coquil, X., Fiorelli, J.L., Blouet, A., Mignolet, C., 2014. Experiencing organic mixed crop dairy systems: a step-by-step-design centred on a long term experiment. In: Bellon, S., Penvern, S. (Eds.), Organic Farming, Prototype for Sustainable Agricultures. Springer, Netherlands, pp. 201-2017.

Cordeau, S., Petit, S., Reboud, X., Chauvel, B., 2011. Sown grass strips harbour high weed diversity but decrease weed richness in adjacent crops. Weed Res. 52, 88-97.

Davis, A.S., Hill, J.D., Chase, C.A., Johanns, A.M., Liebman, M., 2012. Increasing cropping system diversity balances productivity, profitability and environmental health. PLoS One 7, e47149.

Debaeke, P., Munier-Jolain, N., Bertrand, M., Guichard, L., Nolot, J.-M., Faloya, V., Saulas, P., 2009. Iterative design and evaluation of rule-Based cropping systems: methodology and case studies-a review. Agron. Sustain. Dev. 29, 73-86.

Deike, S., Pallutt, B., Christen, O., 2008. Investigations on the energy efficiency of organic and integrated farming with specific emphasis on pesticide use intensity. Eur. J. Agron. 28, 461-470.

Deytieux, V., Nemecek, T., Freiermuth Knuchel, R., Gaillard, G., Munier-Jolain, N.M., 2012. Is Integrated Weed Management efficient for reducing environmental impacts of cropping systems? A case study based on life cycle assessment. Eur. J. Agron. 36, 55-65.

Deytieux, V., Munier-Jolain, N., Caneill, J., 2016. Assessing the sustainability of cropping systems in single- and multi-site studies. A review methods. Eur. J. Agron. 72, 107-126

Directive 2009/128/EC of the European Parliament and of the Council, 2009. Official Journal of the European Union, Available: http://eur-lex.europa.eu/LexUriServ/ LexUriServ.do?uri=OJ:L:2009:309:0071:0086:en:PDF. Accessed 102014.

Doré, T., Sebillotte, M., Meynard, J.M., 1997. A diagnosis method on regional crop yield variations. Agric. Syst. 54, 169-188.

Doré, T., Makowski, D., Malézieux, E., Munier-Jolain, N., Tchamitchian, M., Tittonell, P., 2011. Facing up to the paradigm of ecological intensification in agronomy: revisiting methods, concepts and knowledge. Eur. J. Agron. 34, 197-210.

Drinkwater, L., 2002. Cropping systems research: reconsidering agricultural experimental approaches. HortTechnology 12, 355-361.
Durban, M., Currie, I.D., Kempton, R.A., 2001. Adjusting for fertility and competition in variety trials. J. Agric. Sci. 136, 129-140.

Duru, M., Therond, O., Martin, G., Martin-Clouaire, R., Magne, M.-A., Justes, E., Journet, E.-P., Aubertot, J.-N., Savary, S., Bergez, J.-E., Sarthou, J.P., 2015. How to implement biodiversity-based agriculture to enhance ecosystem services: a review. Agron. Sustain. Dev. 35, http://dx.doi.org/10.1007/s13593-015-0306-1.

El Titi, A., Ipach, W., 1989. Soil fauna in sustainable agriculture: results of an integrated farming system at Lautenbach FRG. Agric. Ecosyst. Environ. 27, 561-572.

El Titi, A., 1991. The Lautenbach-Project 1978-1989: Integrated Wheat production on a commercial arable farm, south-west Germany. In: Firebank, L.G., Carter N., Darbyshire, J.F., Potts, G.R. (Eds.), The Ecology of Temperate Cereal Fields: The 32nd Symposium of the British Ecological Society With the Association of Applied Biologists (Symposia of the British Ecological Society). Blackwell Science Oxford.

Foley, J.A., Ramankutty, N., Brauman, K.A., Cassidy, E.S., Gerber, J.S., Johnston, M., Mueller, N.D., O'Connell, C., Ray, D.K., West, P.C., Balzer, C., Bennett, E.M., Carpenter, S.R., Hill, J., Monfreda, C., Polasky, S., Rockström, J., Sheehan, J. Siebert, S., Tilman, D., Zaks, D.P.M., 2011. Solutions for a cultivated planet. Nature 478, 337-342.

Frampton, G.K., Cilgi, T., 1992. Long-term effects of pesticides on arthropods in UK arable crops: preliminary results from the SCARAB project. Asp. Appl. Biol. 31, 69-76.

García, A.L., Royo-Esnal, A., Torra, J., Cantero-Martinez, C., Recasens, J., 2014. Integrated management of Bromus diandrus in dryland cereal fields under no-till. Weed Res. 54, 408-417.

Gerowitt, B., Wildenhayn, M., 1997. Ökologische und Ökonomische Auswirkungen von Extensivierungsmaßnahmen im Ackerbau -Ergebnisse des Göttinger INTEX-Projektes 1990-94, Goltze, Göttingen (in German).

Glass, E.H., 1975. Integrated pest management: rationale, potential, needs and implementation. Entomol. Soc. Am., 141.

Greig-Smith, P.W., 1991. The Boxworth experience: effects of pesticides on the fauna and flora of cereal fields. In: Firbank, L.G., Carter, N., Darbyshire, J.F., Potts, G.R. (Eds.), The Ecology of Temperate Cereal Fields. Oxford: Blackwell Scientific Publications, pp. 333-372.

Hauggaard-Nielsen, H., Gooding, M., Ambus, P., Corre-Hellou, G., Crozat, Y. Dahlmann, C., Dibet, A., von Fragstein, P., Pristeri, A., Monti, M., Jensen, E.S. 2009. Pea-barley intercropping for efficient symbiotic N2-fixation, soil N acquisition and use of other nutrients in European organic cropping systems. Field Crops Res. 113, 64-71

Holland, J.M., Frampton, G.K., Cilgi, T., Wratten, S.D., 1994. Arable acronyms analysed - a review of integrated arable farming systems research in Western Europe. Ann. Appl. Biol. 125, 399-438.

Hurlbert, S.H., 1984. Pseudoreplication and the design of ecological field experiments. Ecol. Monogr. 54, 187-211.

Jégo, G., Martinez, M., Antigüedad, I., Launay, M., Sanchez-Pérez, J.M., Justes, E., 2008. Evaluation of the impact of various agricultural practices on nitrate leaching under the root zone of potato and sugar beet using the STICS soil-crop model. Sci. Total Environ. 394, 207-221.

Johnston, A.E., 1997. The value of long-term field experiments in agricultural, ecological, and environmental research. Adv. Agron. 59, 291-333.

Kempton, R.A., 1997. Interference between plots. In: Statistical Methods for Plant Variety Evaluation, Series 3. Plant Breeding Series 3. Chapman and Hall.

Korsaeth, A., Eltun, R., 2000. Nitrogen mass balances in conventional, integrated and ecological cropping systems and the relationship between balance calculations and nitrogen runoff in an 8-year field experiment in Norway. Agric. Ecosyst. Environ. 79, 199-214.

Kudsk, P., Jensen, J.E., 2014. Experiences with implementation and adoption of integrated pest management in Denmark. In: Pershin, R., Pimentel, D. (Eds.), Integrated Pest Management: Experiences with Implementation. Springer, pp. 467-485.

Lamichhane, J.R., Dachbrodt-Saaydeh, S., Kudsk, P., Messéan, A., 2016. Towards a reduced reliance on conventional pesticides in European agriculture. Plant Dis. $100,10-24$.

Lazzaro, L., Otto, S., Zanin, G., 2008. Role of hedgerows in intercepting spray drift: evaluation and modelling of the effects. Agric. Ecosyst. Environ. 123, 317-327.

Lechenet, M., Bretagnolle, V., Bockstaller, C., Boissinot, F., Petit, M.-S., Petit, S., Munier-Jolain, N.M., 2014. Reconciling pesticide reduction with economic and environmental sustainability in arable farming. PLoS One 9, 1-10.

Lescourret, F., Magda, D., Richard, G., Adam-Blondon, A.F., Bardy, M., Baudry, J., Doussan, I., Dumont, B., Lefèvre, F., Litrico, I., Martin-Clouaire, R., Montuelle, B. Pellerin, S., Plantegenest, M., Tancoigne, E., Thomas, A., Guyomard, H., Soussana, J.F., 2015. A social-ecological approach to managing multiple agro-ecosystem services. Curr. Opin. Environ. Sust. 14, 68-75.

Marshall, E.J.P., Moonen, A.C., 2002. Field margins in northern Europe: their functions and interactions with agriculture. Agric. Ecosyst. Environ. 89, 5-21.

Matson, P.A., 1997. Agricultural intensification and ecosystem properties. Science 277, 504-509.

Meiss, H., Médiène, S., Waldhardt, R., Caneill, J., Bretagnolle, V., Reboud, X., Munier-Jolain, N., 2010. Perennial lucerne affects weed community trajectories in grain crop rotations. Weed Res., 331-340.

Meynard, J.M., Doré, T., Lucas, P., 2003. Agronomic approach: cropping systems and plant disease. C.R. Biol. 326, 37-46.

Meynard, J.M., Dedieu, B., Bos, A.P., 2012. Re-design and co-design of farming systems An overview of methods and practices. In: Farming Systems Research Into the 21 st Century: The New Dynamic. Springer, pp. 407-432. 
Millenium Ecosystem Assessment, 2005. Ecosystems and Human Well-Being: Synthesis. Isl. Press, Washington, DC.

Moonen, A.C., Bàrberi, P., 2004. Size and composition of the weed seedbank after 7 years of different cover-crop-maize management systems. Weed Res. 44, $163-177$.

Nash, M.A., Thomson, L.J., Hoffmann, A.A., 2008. Effect of remnant vegetation, pesticides, and farm management on abundance of the beneficial predator Notonomus gravis (Chaudoir) (Coleoptera: Carabidae). Biol. Control 46, 83-93.

Norman, D.W., Frankenberger, T.R., Hildebrandt, P.E., 1994. Agricultural research in developed countries: past, present and future of farming systems research and extension. J. Prod. Agric. 7, 124-131.

Papy, F., Malézieux, E., Trébuil, G., Jaeger, M., 2001. Interdependence of cultural systems in exploitation. In: Modélisation Des Agroécosystèmes et Aide à La Décision. La Librairie du Cirad, pp. 51-74, in French.

Papy, F., 2008. Le système de culture: un concept riche de sens pour penser le futur. Cah. Agric. 17, 263-269, in French.

Pardo, G., Riravololona, M., Munier-Jolain, N.M., 2010. Using a farming system model to evaluate cropping system prototypes: are labour constraints and economic performances hampering the adoption of Integrated Weed Management? Eur J. Agron. 33, 24-32.

Peigné, J., Cannavaciuolo, M., Gautronneau, Y., Aveline, A., Giteau, J.L., Cluzeau, D., 2009. Earthworm populations under different tillage systems in organic farming. Soil Till. Res. 104, 207-214.

Perks, D.A., Lane, P., 1990. Towards a low input system minimising agrochemicals and nitrogen. Swiss J. Agric. Sci. 29, 395-396, TALISMAN.

Rasmussen, I., 2004. The effect of sowing date, stale seedbed, row width and mechanical weed control on weeds and yields of organic winter wheat. Weed Res. 94, 12-20.

Reganold, J.P., Glover, J.D., Andrews, P.K., Hinman, H.R., 2001. Sustainability of three apple production systems. Nature 410, 926-930.

Riley, H., Pommeresche, R., Eltun, R., Hansen, S., Korsaeth, A., 2008. Soil structure, organic matter and earthworm activity in a comparison of cropping systems with contrasting tillage rotations, fertilizer levels and manure use. Agric. Ecosyst. Environ. 124, 275-284.

Rossing, W.A.H., Meynard, J.M., Van Ittersum, M.K., 1997. Model-based explorations to support development of sustainable farming systems: case studies from France and the Netherlands. Dev. Crop Sci. 25, 339-351.

Sainju, U.M., Senwo, Z.N., Nyakatawa, E.Z., Tazisong, I.A., Reddy, K.C., 2008. Soil carbon and nitrogen sequestration as affected by long-term tillage cropping systems, and nitrogen fertilizer sources. Agric. Ecosyst. Environ. 127, 234-240.

Schillinger, W.F., 2010. Practical lessons for successful long-term cropping systems experiments. Renew. Agric. Food Syst. 26, 1-3.
Sebillotte, M., Soler, L.G., 1988. Le concept de modèle général et la compréhension du comportement de l'agriculteur in French.

Sebillotte, M., 1974. Agronomie et agriculture Essai d'analyse des tâches de l'agronome. Cahiers de l'ORSTOM 24, 3-25, in French.

Sebillotte, M., 1978. Itinéraires techniques et évolution de la pensée agronomique. Comptes Rendus des Séances de l'Académie d'Agriculture de France, in French.

Sebillotte, M., 1990. Some concepts for analysing farming and cropping systems and for understanding their different effects. In: Scaife, A. (Ed.), In Proc. of the 1st Congress European Society of Agronomy, Paris, 5-7 Th December., pp. 1-16.

Soane, B.D., Ball, B.C., 1998. Review of management and conduct of long-term tillage studies with special reference to a 25-yr experiment on barley in Scotland. Soil Till. Res. 45, 17-37.

Steinmann, H.-H., Gerowitt, B. (Eds.), 2000. Ackerbau in der Kulturlandschaft Funktionen und Leistungen: Ergebnisse des Göttinger INTEX-Projektes. Mecke Druck, Duderstadt (ISBN: 3-932752-65-1).

Symondson, W.O., Glen, D.M., Ives, A.R., Langdon, C.J., Wiltshire, C.W., 2002. Dynamics of the relationship between a generalist predator and slugs over five years. Ecology 83, 137-147.

Tomich, T.P., Brodt, S., Ferris, H., Galt, R., Horwath, W.R., Kebreab, E., Leveau, J.H.J., Liptzin, D., Lubell, M., Merel, P., Michelmore, R., Rosenstock, T., Scow, K., Six, J., Williams, N., Yang, L., 2011. Agroecology: a review from a global-change perspective. Annu. Rev. Environ. Res. 36, 193-222.

Tricault, Y., Darmency, H., Colbach, N., 2009. Identifying key components of weed beet management using sensitivity analyses of the GeneSys-Beet model in GM sugar beet. Weed Res. 49, 581-591.

Vereijken, P., 1989. From integrated control to integrated farming, an experimental approach. Agric. Ecosyst. Environ. 26, 37-63.

Viaux, P., Fourgeroux, A., Hilaire, A., Cavelier, A., Lescar, L., 1989. Planning of integrated farming systems experiments in France. In: IOBC/WPRS Bulletin 1989/XII/5. Wageningen, The Netherlands (pp. 1620).

Weihrich, H., 1982. The TOWS matrix-a tool for situational analysis. Long Range Plann. 15, 54-66.

Wezel, A., Doré, T., Bellon, S., David, C., Francis, C., Vallod, D., 2009. Agroecology as a science, a movement and a practice. A review. Agron. Sustain. Dev. 29, 503-515.

Wijnands, F.G., Vereijken, P., 1992. Region-wise development of prototypes of integrated arable farming and outdoor horticulture. Neth. J. Agric. Sci. 40, 225-238.

Zhang, W., Ricketts, T.H., Kremen, C., Carney, K., Swinton, S.M., 2007. Ecosystem services and dis-services to agriculture. Ecol. Econ. 64, 253-260.

Zulian, G., Maes, J., Paracchini, M., 2013. Linking land cover data and crop yields for mapping and assessment of pollination services in Europe. Land 2, 472-492. 